\title{
Correlation between PTEN gene polymorphism and oral squamous cell carcinoma
}

\author{
MIN LIU ${ }^{1}$, HONGNING SONG ${ }^{1}$, ZAICHEN XING $^{1}$, GUO LU $^{2}$, \\ JUNFU LI ${ }^{1}$ and DAIYUN CHEN ${ }^{1}$ \\ ${ }^{1}$ Department of Stomatology, Affiliated Hospital of Taishan Medical University, Taian, \\ Shandong 271000; ${ }^{2}$ First People's Hospital in Ningyang County, Taian, Shandong 271400, P.R. China
}

Received April 2, 2019; Accepted May 28, 2019

DOI: $10.3892 / 01.2019 .10526$

\begin{abstract}
Correlation between phosphatase and tensin homolog deleted on chromosome ten (PTEN) gene polymorphism and oral squamous cell carcinoma (OSCC) was investigated. A total of 33 OSCC patients were studied and 33 healthy individuals were included as the control group. Correlation between PTEN gene and OSCC was explored via quantitative polymerase chain reaction (qPCR), immunohistochemistry and western blot analysis. The PTEN gene polymorphism was detected via PCR-restriction fragment length polymorphism (PCR-RFLP), and its correlation with OSCC was explored. The immunohistochemical assay showed that the PTEN protein expression level significantly declined in OSCC patients $(2.37 \pm 1.01 \mu \mathrm{g} / \mathrm{l})$ compared with that in healthy subjects $(3.09 \pm 0.95 \mu \mathrm{g} / \mathrm{l})$. There was no significant difference in the rs2943773 genotype between control and experimental group $\left(\chi^{2}=0.863, \mathrm{P}=0.712\right)$, but there was a significant difference in the rs9651495 genotype between the two groups $(\mathrm{P}<0.05)$. The $\mathrm{C} / \mathrm{C}$ genotype frequency of rs 9651495 in OSCC patients $(50.15 \%)$ was significantly higher than that in healthy subjects $(23.71 \%)(\mathrm{P}<0.05)$. The $\mathrm{C} / \mathrm{T}$ genotype frequency of rs9651495 had no significant difference between the two groups (18.52 vs. 19.01\%) $(\mathrm{P}>0.05)$. The $\mathrm{T} / \mathrm{T}$ genotype frequency of rs9651495 in OSCC patients (31.33\%) was obviously lower than that in healthy subjects $(57.19 \%)(\mathrm{P}<0.05)$. According to statistics, the PTEN protein expression level in patients with $\mathrm{C} / \mathrm{C}$ genotype was remarkably lower than that in patients with other genotypes. There is a correlation between PTEN gene polymorphism and OSCC. Thereby, the higher $\mathrm{C} / \mathrm{C}$ genotype frequency corresponds to the lower PTEN protein expression level, thus inducing OSCC.
\end{abstract}

Correspondence to: Dr Daiyun Chen, Department of Stomatology, Affiliated Hospital of Taishan Medical University, 706 Taishan Avenue, Taishan, Taian, Shandong 271000, P.R. China

E-mail: cybpp452@163.com

Key words: oral squamous cell carcinoma, PTEN, gene polymorphism, immunohistochemistry, genotype

\section{Introduction}

Since ancient times, China has been well known for its tasty food. There are large differences in the dietary habit among different regions in China due to large population, vast territory and different nationalities (1-3), which greatly enriches material life. However, the extremely complicated dietary habits also lead to high incidence rate of diet-related diseases, of which oral carcinoma is a malignant tumor with a high incidence rate, mainly oral squamous cell carcinoma (OSCC) in China $(4,5)$.

According to statistical data, OSCC accounts for more than $90 \%$ of oral carcinoma, so enhancing the research on OSCC has important theoretical and practical significance in China. Currently, the operation, including radiotherapy and chemotherapy, is dominated in the treatment of OSCC. However, metastasis occurs more easily in OSCC cells than general tumor cells, so there is no effective treatment method at present $(6,7)$. In recent years, related studies have found that the phosphatase and tensin homolog deleted on chromosome ten (PTEN) has close correlations with the incidence of a variety of tumors, including breast cancer and melanoma, and its expression declines obviously in the above tumor cells $(8,9)$.

On this basis, the present study investigated whether there is a correlation between PTEN gene and OSCC, and further explored whether there is also a correlation between PTEN gene polymorphism and OSCC, aiming to provide a certain theoretical and experimental basis for the treatment of OSCC.

\section{Patients and methods}

General data. In the experiment, 33 OSCC patients treated in the Affiliated Hospital of Taishan Medical University (Taian, China) from January 2016 to January 2018 were selected as the experimental group, including 18 males and 15 females, aged 45 years on average, while 33 healthy subjects were selected as the control group, including 17 males and 16 females, aged 45 years on average. The experimental scheme was discussed and approved by the Academic Committee, and agreed by the family members.

This study was approved by the Ethics Committee of Affiliated Hospital of Taishan Medical University. Patients who participated in this research had complete clinical data. 
The signed informed consents were obtained from the patients or the guardians.

The following experimental reagents were used: Fluorescence quantitative polymerase chain reaction (PCR) reagent and ribonucleic acid (RNA) extraction reagent were purchased from Takara and animal cell protein extraction kit was purchased from Thermo Fisher Scientific, Inc. Streptomycin-peroxidase (S-P) kit and corresponding antibodies were purchased from Thermo Fisher Scientific, Inc. Genome extraction kit was purchased from AXYGEN and other reagents and consumables were purchased from Sangon Biotech Co., Ltd.

\section{Methods}

\section{Quantitative PCR}

$R N A$ extraction. After $5 \mathrm{ml}$ of peripheral blood was drawn from healthy subjects and OSCC patients and centrifuged at $1,000 \mathrm{x} \mathrm{g}$ at $4^{\circ} \mathrm{C}$ for $5 \mathrm{~min}, \mathrm{RNA}$ was extracted according to the instructions of RNA extraction kit (10).

Quantitative PCR. To detect the messenger RNA (mRNA) expression of PTEN gene in different samples, SYBR-Green 1 staining was performed in accordance with the instructions. The reaction system volume was in total $25 \mu 1$, pre-denaturation at $95^{\circ} \mathrm{C}$ for $5 \mathrm{~min}$, denaturation at $95^{\circ} \mathrm{C}$ for $30 \mathrm{sec}$, annealing at $60^{\circ}$ for $45 \mathrm{sec}$, extension at $72^{\circ} \mathrm{C}$ for $3 \mathrm{~min}$, with 35 cycles, and then extension at $72^{\circ} \mathrm{C}$ for $5 \mathrm{~min}$. PCR products were stored at $4^{\circ} \mathrm{C}$. With GAPDH as the internal control, the relative expression level of miR-204 was calculated by $2^{-\Delta \Delta \mathrm{Cq}}$ method (11). The sequences are shown in Table I.

Western blot analysis. The total protein was extracted from the sample using the AXYGEN animal cell protein extraction kit. According to the instructions $0.5 \mathrm{mg}$ of different research samples were accurately taken and quantified via Coomassie blue staining. After treatment, $20 \mu \mathrm{l}$ samples were taken for sodium dodecyl sulfate polyacrylamide gel electrophoresis $(10 \%)$. Then the protein was transferred onto a polyvinylidene difluoride membrane, sealed for $2 \mathrm{~h}$ at $4^{\circ} \mathrm{C}$. Bull serum albumin (BSA), blocking buffer (5\%) was used as the blocking reagent. Then the membrane was incubated with the primary antibody (shown below) at $20^{\circ} \mathrm{C}$ for $2 \mathrm{~h}$, incubated again with the secondary antibody at room temperature for $2 \mathrm{~h}$, and washed with eluent 5 times (10 $\mathrm{min} /$ time). Rabbit monoclonal anti-PTEN antibody (cat. no. ab32199; dil, 1:500); rabbit polyclonal GAPDH antibody (cat. no. ab37168; dil, 1:500) and secondary goat anti-rabbit (HRP) IgG antibody (cat. no. ab6721; dil, 1:2,000) were all purchased from Abcam. Finally, the color was developed using the developing solution.

Immunohistochemical assay. In this study, the lesion tissue samples were routinely incubated with the antibody and stained with S-P. The immunohistochemical evaluation criteria were: membrane staining $<10 \%$ or negative after staining (negative), and only membrane staining or $>10 \%$ (positive) (12).

\section{Gene polymorphism detection}

Genome extraction. After $5 \mathrm{ml}$ peripheral blood was drawn from healthy subjects and OSCC patients and centrifuged
Table I. Primer sequences in quantitative PCR.

\begin{tabular}{ll}
\hline Primers & \multicolumn{1}{c}{ Sequences } \\
\hline rs2943773RT-F & ATGCTAGCTGATCGATCAGCTA \\
rs2943773RT-R & CGTAGCTAGTATACGTACGCTACG \\
rs9651495RT-F & CGTAGCTAGCTAGCATCGATACG \\
rs9651495RT-R & CGTAGCTAGCATCGAGGCTACGAGC \\
GAPDH-F & CGTAGGGCTAGCTAGCTAGATAC \\
GAPDH-R & CGTAGCTGAGAGTTAGCTAGCATC
\end{tabular}

Table II. Primers in PCR-RFLP.

\begin{tabular}{ll}
\hline Primers & \multicolumn{1}{c}{ Sequences } \\
\hline rs2943773-F & ATCGTAGCTAGAGCATCGATCGAC \\
rs2943773-R & CGATGCTACGATCGAGACTAGCTA \\
rs9651495-F & TGCATCGAGGCGAGCGACTAGATA \\
rs9651495-R & GCTAGCATGGAGCAGCGATCAGCATG \\
\hline
\end{tabular}

at $1,000 \mathrm{x} \mathrm{g}$ and $4^{\circ} \mathrm{C}$ for $5 \mathrm{~min}$, and genome was extracted according to the instructions of the kit (13).

PCR-restriction fragment length polymorphism (RFLP). The primers used in this study were produced by Sangon Biotech Co., Ltd., and the primer sequences are shown in Table II.

The PCR products obtained were collected and connected according to the gel recovery and T-vector connection operations in the Molecular Cloning Manual, and added with DH5 $\alpha$, followed by colony PCR verification and sequencing.

Sequencing. In the present study, the Escherichia coli transfected with the target plasmid was used as a template for colony PCR verification, and the gene was sent to Sangon Biotech Co., Ltd., for sequencing.

Statistical analysis. The experimental data in this study were processed and analyzed using Statistical Product and Service Solutions (SPSS) 20.0 software (IBM, Armonk, NY, USA). The test level was $\alpha=0.05, \mathrm{P}<0.05$ indicates that the difference was significant, and $\mathrm{P}<0.01$ indicates that the difference was very significant.

\section{Results}

Difference in mRNA expression level of PTEN between healthy subjects and OSCC patients. Whether there was a difference in the PTEN mRNA level between healthy subjects and OSCC patients was detected via quantitative PCR. As shown in Fig. 1, there was no significant difference in the PTEN mRNA expression level between healthy subjects and OSCC patients $(\mathrm{P}>0.05)$, indicating that the PTEN mRNA level had no difference between healthy subjects and OSCC patients. 
Table III. Immunohistochemical results of PTEN gene between healthy people and OSCC patients.

\begin{tabular}{lccc}
\hline Groups & $\begin{array}{c}\text { Number of } \\
\text { positive cells }\end{array}$ & $\begin{array}{c}\text { Ratio of positive } \\
\text { cells in the total }(\%)\end{array}$ & $\begin{array}{c}\text { Number of } \\
\text { negative cells }\end{array}$ \\
\hline Control & $68 / 100$ cells & 68 & $30 / 100$ cells \\
Experimental & $28 / 100$ cells & 28 & $70 / 100$ cells \\
P-value & & $0.015<0.05$ & \\
\hline
\end{tabular}

$\mathrm{P}<0.05$, the difference is significant.

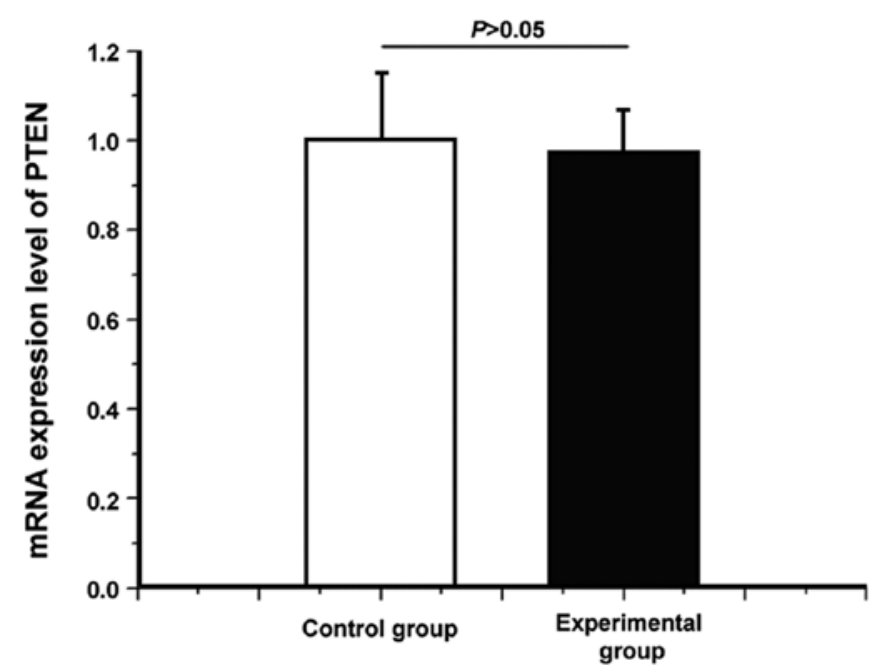

Figure 1. Difference in mRNA expression level of PTEN between healthy subjects and OSCC patients. There is no significant difference in the PTEN mRNA expression level between healthy subjects and OSCC patients $(\mathrm{P}>0.05)$.

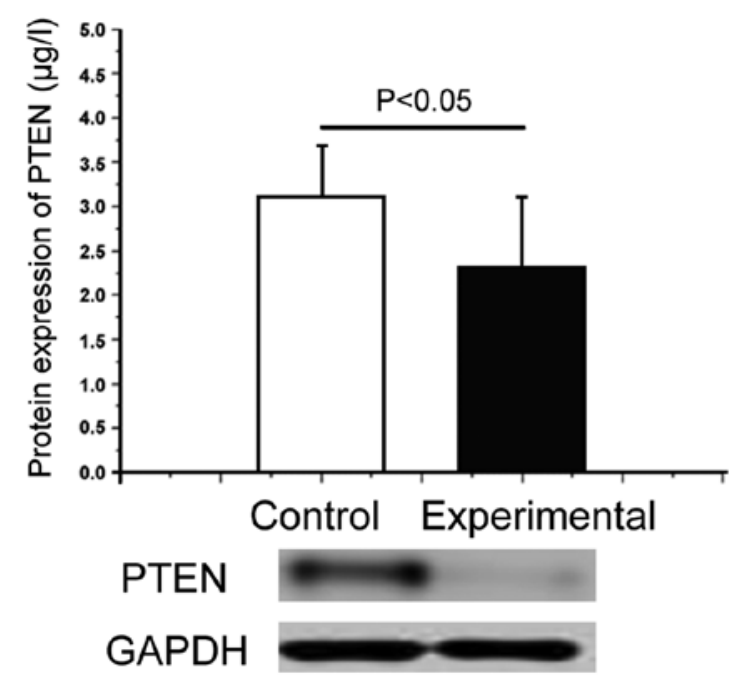

Figure 2. Difference in protein expression level of PTEN between healthy subjects and OSCC patients. There is a significant difference in the PTEN protein expression level between healthy subjects and OSCC patients $(\mathrm{P}<0.05)$.

Difference in protein expression level of PTEN between healthy subjects and OSCC patients. The total protein extracted from the blood in healthy subjects and OSCC patients were used as the objects of study, and the difference in PTEN protein
Table IV. Determination of rs2943773 genotype of PTEN gene in healthy people and OSCC patients.

\begin{tabular}{lccc}
\hline & \multicolumn{3}{c}{ Genotype } \\
\cline { 2 - 4 } Groups & $\mathrm{C} / \mathrm{C}(\%)$ & $\mathrm{C} / \mathrm{T}(\%)$ & $\mathrm{T} / \mathrm{T}(\%)$ \\
\hline Control & 42.5 & 38.4 & 19.1 \\
Experimental & 40.3 & 35.6 & 24.1 \\
P-value & $0.327>0.05$ & $0.291>0.05$ & $0.185>0.05$ \\
\hline
\end{tabular}

$\mathrm{P}<0.05$, the difference is significant.

expression level in different subjects was detected via western blot analysis. As shown in Fig. 2, the PTEN protein expression level significantly declined in OSCC patients $(2.37 \pm 1.01 \mu \mathrm{g} / \mathrm{l})$ compared with that in healthy subjects $(3.09 \pm 0.95 \mu \mathrm{g} / \mathrm{l})$, and there was a significant difference $(\mathrm{P}<0.05)$, indicating that the decrease in the PTEN protein expression level was negatively correlated with OSCC. At the same time, the results of quantitative PCR revealed that PTEN was correlated with OSCC at the protein level, but not at the mRNA level, suggesting that OSCC affects the translation process of PTEN gene without affecting its gene transcription process.

Immunohistochemical detection of PTEN gene between healthy subjects and OSCC patients. The analysis of immunohistochemical results of samples from healthy subjects and OSCC patients showed that the expression level of PTEN in oral cells of healthy subjects was higher than that of OSCC patients. In other words, the proportion of PTEN-positive cells in the total in control group (68\%) was significantly higher than that in experimental group (28\%), and there was a significant difference $(\mathrm{P}=0.015<0.05)$, which is consistent with the protein detection results (Fig. 3 and Table III).

Determination of rs2943773 genotype of PTEN gene in healthy subjects and OSCC patients. The total DNAs extracted in control and experimental group were used as templates, and then the PTEN gene was amplified and sequenced. It was found that there was no significant difference in the rs2943773 genotype between the control and experimental groups $\left(\chi^{2}=0.863, \mathrm{P}=0.712\right)$, indicating that the difference in PTEN protein expression between healthy subjects and OSCC patients is not caused by the difference in rs2943773 (Table IV). 
Control

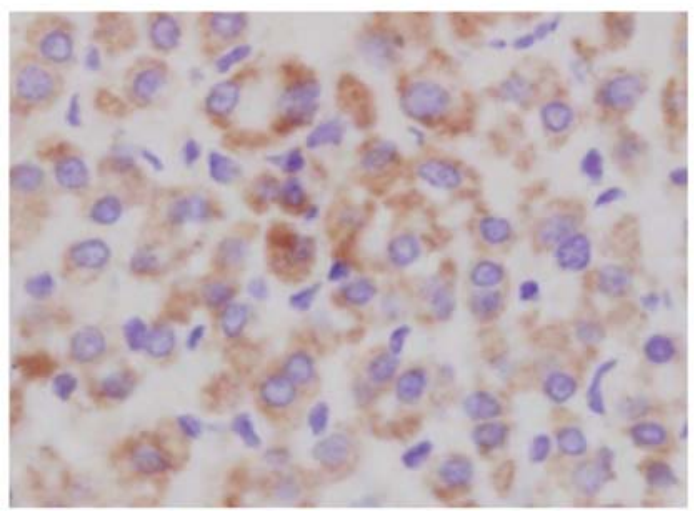

Experimental

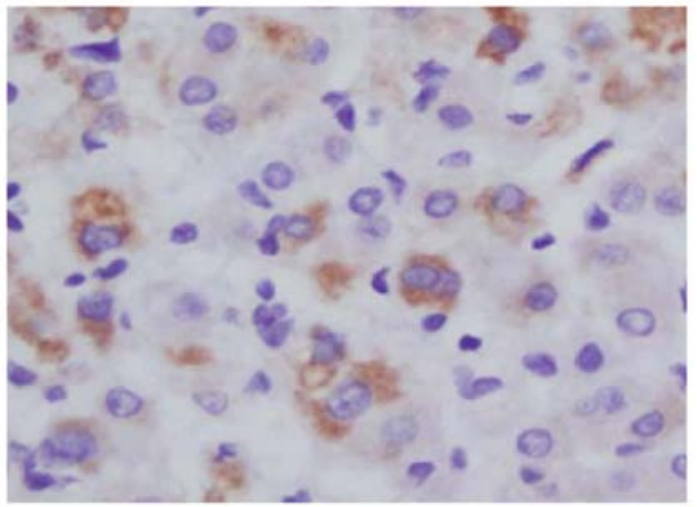

Figure 3. Immunohistochemical detection of PTEN gene in healthy subjects and OSCC patients. The results of immunohistochemical detection show that the $P T E N$ gene has a significant difference between healthy subjects and OSCC patients $(\mathrm{P}<0.05)$.

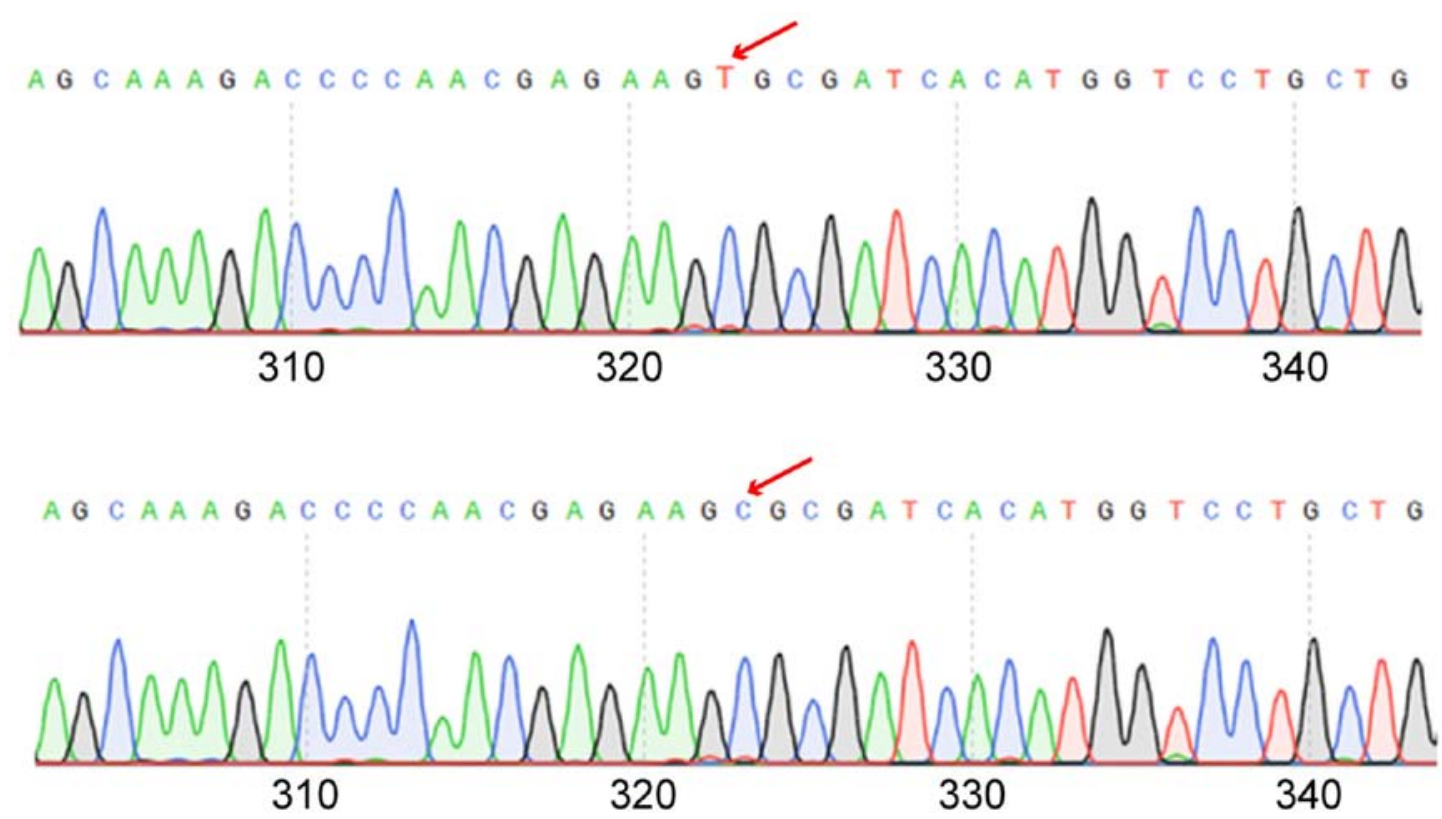

Figure 4. Determination of rs9651495 genotype of PTEN gene in healthy subjects and OSCC patients. There are different genotypes in rs9651495 in healthy subjects and OSCC patients, but the proportion of different genotypes is significantly different $(\mathrm{P}<0.05)$.

Table V. Determination of rs9651495 genotype of PTEN gene in healthy subjects and OSCC patients.

\begin{tabular}{lccc}
\hline & \multicolumn{3}{c}{ Genotype } \\
\cline { 2 - 4 } Groups & $\mathrm{C} / \mathrm{C}(\%)$ & $\mathrm{C} / \mathrm{T}(\%)$ & $\mathrm{T} / \mathrm{T}(\%)$ \\
\hline Control & 23.71 & 19.01 & 57.19 \\
Experimental & 50.15 & 18.52 & 31.33 \\
P-value & $0.012<0.05$ & $0.129>0.05$ & $0.023<0.05$ \\
\hline
\end{tabular}

$\mathrm{P}<0.05$, the difference is significant.

Determination of rs 9651495 genotype of PTEN gene in healthy subjects and OSCC patients. The genome extracted in the control and experimental groups was used as a template, and then the rs9651495 was amplified and sequenced. It was found that there was a significant difference in the rs 9651495 genotype between the two groups $(\mathrm{P}<0.05)$ (Fig. 4). The $\mathrm{C} / \mathrm{C}$ genotype frequency of rs9651495 in OSCC patients $(50.15 \%)$ was significantly higher than that in healthy subjects $(23.71 \%)$, showing a significant difference $(\mathrm{P}<0.05)$. The $\mathrm{C} / \mathrm{T}$ genotype frequency of rs 9651495 had no significant difference between the two groups (18.52 vs. 19.01\%) ( $\mathrm{P}>0.05)$. The T/T genotype frequency of rs9651495 in OSCC patients (31.33\%) was obviously lower than that in healthy subjects (57.19\%), displaying a significant difference $(\mathrm{P}<0.05)$, suggesting the correlation between rs9651495 locus polymorphism of PTEN gene and OSCC (Table V).

Detection of correlation between PTEN gene polymorphism and genotype. To explore the correlation between OSCC and PTEN polymorphism, the figure was plotted with the ratio of $\mathrm{C} / \mathrm{C}$ of rs9651495 in PTEN gene as the abscissa and the 
presence or absence of OSCC as the ordinate. As shown the proportion of OSCC patients was significantly increased with the increase of $\mathrm{C} / \mathrm{C}$ ratio (Table $\mathrm{V}$ ), suggesting that there is a significant correlation between rs9651495 locus polymorphism of PTEN gene and OSCC.

\section{Discussion}

The morbidity rate of OSCC, an oral disease seriously harming human health, has shown an increasing trend year by year (14-16). According to statistical data, the incidence rate of OSCC in China is significantly higher than that in other countries due to large population and different dietary habits $(17,18)$. Therefore, enhancing the research on OSCC has important medical significance. In the present study, OSCC patients treated in the hospital and healthy subjects were selected as the objects to investigate the correlation between OSCC and PTEN gene polymorphism. It was found via quantitative PCR that there was no significant difference in the expression level of PTEN gene between healthy subjects and OSCC patients $(\mathrm{P}>0.05)$, indicating that OSCC does not inhibit the PTEN gene transcription level. Then the PTEN protein expression level was detected in the experimental and control groups via western blot analysis. The results showed that the PTEN protein expression level significantly declined in OSCC patients $(2.37 \pm 1.01 \mu \mathrm{g} / \mathrm{l})$ compared with that in healthy subjects $(3.09 \pm 0.95 \mu \mathrm{g} / \mathrm{l})$, and there was a significant difference $(\mathrm{P}<0.05)$, indicating that PTEN gene is correlated with OSCC. The immunohistochemical results were consistent with the protein detection results, suggesting that OSCC can inhibit the translation process of PTEN gene. However, how this process occurs remains unclear $(19,20)$. It is evident through the above experiments that there is a correlation between OSCC and PTEN gene, namely, PTEN expression is low in OSCC patients. Based on these results, the genome extracted from healthy subjects and OSCC patients was used as a template, and then the different regions of the PTEN gene were amplified and sequenced. It was found that there was a significant difference in the rs9651495 genotype between the control group and experimental group $(\mathrm{P}<0.05)$. The $\mathrm{C} / \mathrm{C}$ genotype frequency of rs9651495 in OSCC patients $(50.15 \%)$ was significantly higher than that in healthy subjects $(23.71 \%)$, showing a significant difference $(\mathrm{P}<0.05)$. The $\mathrm{C} / \mathrm{T}$ genotype frequency of rs9651495 had no significant difference between the control and experimental groups (18.52 vs. $19.01 \%)(\mathrm{P}>0.05)$. The $\mathrm{T} / \mathrm{T}$ genotype frequency of rs9651495 in OSCC patients $(31.33 \%)$ was obviously lower than that in healthy subjects $(57.19 \%)$, displaying a significant difference $(\mathrm{P}<0.05)$. The above results demonstrate that there is a positive correlation between rs9651495 locus polymorphism of PTEN gene and OSCC, and OSCC is induced more easily in subjects with higher $\mathrm{C} / \mathrm{C}$ genotype frequency.

In conclusion, the higher $\mathrm{C} / \mathrm{C}$ genotype frequency corresponds to the lower PTEN protein expression level, thus inducing OSCC.

\section{Acknowledgements}

Not applicable.

\section{Funding}

This study was supported by the Project of Taian Science and Technology Development Plan (2017NS0134).

\section{Availability of data and materials}

All data generated or analyzed during this study are included in this published article.

\section{Authors' contributions}

ML and DC designed the study and performed the experiments. ML, HS and ZX collected the data, GL and JL analyzed the data, and ML and DC prepared the manuscript. All the authors read and approved the final manuscript.

\section{Ethics approval and consent to participate}

This study was approved by the Ethics Committee of Affiliated Hospital of Taishan Medical University (Taian, China). Patients who participated in this research had complete clinical data. The signed informed consents were obtained from the patients or the guardians.

\section{Patient consent for publication}

Not applicable.

\section{Competing interests}

The authors declare they had no competing interests.

\section{References}

1. Siegel R, Ward E, Brawley O and Jemal A: Cancer statistics, 2011: The impact of eliminating socioeconomic and racial disparities on premature cancer deaths. CA Cancer J Clin 61: 212-236, 2011.

2. Tsai LL, Yu CC, Chang YC, Yu CH and Chou MY: Markedly increased Oct4 and Nanog expression correlates with cisplatin resistance in oral squamous cell carcinoma. J Oral Pathol Med 40: 621-628, 2011.

3. Bhaijee F, Pepper DJ, Pitman KT and Bell D: Cancer stem cells in head and neck squamous cell carcinoma: A review of current knowledge and future applications. Head Neck 34: 894-899, 2012.

4. Sayed SI, Dwivedi RC, Katna R, Garg A, Pathak KA, Nutting CM, Rhys-Evans P, Harrington KJ and Kazi R: Implications of understanding cancer stem cell (CSC) biology in head and neck squamous cell cancer. Oral Oncol 47: 237-243, 2011.

5. Wu SJ, Huang SY, Lin CT, Lin YJ, Chang CJ and Tien HF: The incidence of chronic lymphocytic leukemia in Taiwan, 1986-2005: A distinct increasing trend with birth-cohort effect. Blood 116: 4430-4435, 2010.

6. Sun C and Li J: Expression of MiRNA-137 in oral squamous cell carcinoma and its clinical significance. J BUON 23: 167-172, 2018.

7. Wiestner A: Emerging role of kinase-targeted strategies in chronic lymphocytic leukemia. Blood 120: 4684-4691, 2012.

8. Albers AE, Chen C, Köberle B, Qian X, Klussmann JP Wollenberg B and Kaufmann AM: Stem cells in squamous head and neck cancer. Crit Rev Oncol Hematol 81: 224-240, 2012.

9. White AC, Tran K, Khuu J, Dang C, Cui Y, Binder SW and Lowry WE: Defining the origins of Ras/p53-mediated squamous cell carcinoma. Proc Natl Acad Sci USA 108: 7425-7430, 2011.

10. Lapouge G, Youssef KK, Vokaer B, Achouri Y, Michaux C, Sotiropoulou PA and Blanpain C: Identifying the cellular origin of squamous skin tumors. Proc Natl Acad Sci USA 108: 7431-7436, 2011. 
11. Livak KJ and Scmittgen TD: Analysis of relative gene expression data using real-time quantitative PCR and the 2(-Delta Delta C(T)) method. Methods 25: 402-408, 2001.

12. Van Keymeulen A and Blanpain C: Tracing epithelial stem cells during development, homeostasis, and repair. J Cell Biol 197: 575-584, 2012.

13. Zou ZJ, Zhang R, Fan L, Wang L, Fang C, Zhang LN, Yang S, Li YY, Li JY and Xu W: Low expression level of phosphatase and tensin homolog deleted on chromosome ten predicts poor prognosis in chronic lymphocytic leukemia. Leuk Lymphoma 54: 1159-1164, 2013.

14. Zhu DX, Zhu W, Fang C, Fan L, Zou ZJ, Wang YH, Liu P, Hong M, Miao KR, Liu P, et al: miR-181a/b significantly enhances drug sensitivity in chronic lymphocytic leukemia cells via targeting multiple anti-apoptosis genes. Carcinogenesis 33: 1294-1301, 2012.

15. Doupé DP, Klein AM, Simons BD and Jones PH: The ordered architecture of murine ear epidermis is maintained by progenitor cells with random fate. Dev Cell 18: 317-323, 2010.

16. HoellenriegelJ,Meadows SA,SivinaM,WierdaWG, Kantarjian H, Keating MJ, Giese N, O'Brien S, Yu A, Miller LL, et al: The phosphoinositide 3'-kinase delta inhibitor, CAL-101, inhibits B-cell receptor signaling and chemokine networks in chronic lymphocytic leukemia. Blood 118: 3603-3612, 2011.
17. Fabbri M, Bottoni A, Shimizu M, Spizzo R, Nicoloso MS, Rossi S, Barbarotto E, Cimmino A, Adair B, Wojcik SE, et al: Association of a microRNA/TP53 feedback circuitry with pathogenesis and outcome of B-cell chronic lymphocytic leukemia. JAMA 305: 59-67, 2011

18. Jotta PY, Ganazza MA, Silva A, Viana MB, da Silva MJ, Zambaldi LJ, Barata JT, Brandalise SR and Yunes JA: Negative prognostic impact of PTEN mutation in pediatric T-cell acute lymphoblastic leukemia. Leukemia 24: 239-242, 2010.

19. Jjingo D, Conley AB, Yi SV, Lunyak VV and Jordan IK: On the presence and role of human gene-body DNA methylation. Oncotarget 3: 462-474, 2012.

20. Khan H, Vale C, Bhagat T and Verma A: Role of DNA methylation in the pathogenesis and treatment of myelodysplastic syndromes. Semin Hematol 50: 16-37, 2013.

(1) (9) This work is licensed under a Creative Commons Attribution-NonCommercial-NoDerivatives 4.0 International (CC BY-NC-ND 4.0) License. 